\title{
Mutações bastardas da comunicação ${ }^{1}$ Bastard mutations of communication
}

\author{
OMAR RINCÓNa \\ Universidad de los Andes, Mestrado em Jornalismo e em Humanidades Digitais. Bogotá, Colômbia
}

\section{RESUMO}

Os discursos e as agendas do século XX já não são úteis para explicar as mudanças da nossa época. Torna-se difícil explicar essa sociedade zombie - de vivos mortos no consumo, distantes da política e do humanismo -; com meios de comunicação desconectados das pessoas e convertidos em atores políticos; um capitalismo que premia a injustiça social e o cinismo; um sistema de justiça que é cada vez mais de direita e segue o deus moral do capital. Para esse novo mundo, precisamos levantar diferentes discursos e conceitos. É disso que trata o artigo: encontrar caminhos a partir dos quais a comunicação tem sido pensada na América Latina, olhar novamente os mapas noturnos de Martín-Barbero, desenvolver ideias sobre a mutação da comunicação.

Palavras-chave: Comunicação, cultura, América Latina, Martín-Barbero, mutações

\begin{abstract}
The discourses and agendas of the twentieth century are no longer useful in explaining the changes of our time. It is difficult to explain this zombie society - of living dead people in consumption, far from politics and humanism; with media disconnected from the people and converted into political actors; a capitalism that rewards social injustice and cynicism; a system of justice that is increasingly right-wing and follows the god of capital. For this new world, we need to raise different discourses and concepts. This is what the article is about: finding ways from which communication has been thought in Latin America, looking again at Martín-Barbero's nighttime maps, developing ideas about the mutation of communication.
\end{abstract}

Keywords: Communication, culture, Latin America, Martín-Barbero, mutations 
$\mathrm{B}$ EM-VINDOS À AMÉRICA LATINA. Bem-vindos à Colômbia. Bem-vindos ao lugar onde temos pensado de outro modo a comunicação. Um modo que parte mais das pessoas e menos dos meios; mais das identidades, menos da indústria.

Obrigado à International Association for Media and Communication Research (IAMCR), que me permite levar a voz da Colômbia e contar suas histórias latino-americanas. Espero que, em minha voz, ressoem bastardamente os que têm pensado, criado e inventado a América Latina no campo da comunicação.

Embora se espere que sejamos realismo mágico e García Márquez para criar universos fascinantes e maravilhosos... Embora se espere, como disse o ensaísta mexicano Juan Villoro, que sejamos esse parque temático, imaginado desde o período colonial, que se chama América Latina... Embora se anseie que sejamos mulheres que voam pelos ares ao fazer amor; cocaína colombiana construindo imaginários cool; telenovelas cheias de mulheres morrendo de amor e violência; músicas tropicais que nos fazem dançar e habitam os corpos exóticos; praias e selva onde se perde a vergonha moderna... Embora se espere que sejamos isso, no que os olhares do Norte nos têm convertido (e talvez o sejamos, ou também sejamos isso, afinal alguém é o relato que constrói e que constroem dele)... Aqui escolhi ser um cronista do Sul.

Por isso quero fazer uma breve crônica desses latino-americanos que têm feito outra coisa da comunicação. Vou lhes contar uma história em três cenas: primeiro, nossos vanguardistas da comunicação; depois, os mapas noturnos e as mediações diurnas do mestre Martín-Barbero; para terminar apresentarei alguns vislumbres bastardos para compreender a atual mutação cultural da comunicação.

Bem-vindos ao lugar onde a comunicação não é somente meios ou entretenimento, mas sim cultura, povo, liberdade, resistência, cumplicidade, criação. Bem-vindos a isso, que não somos Jollywood.

\section{CENA 1. OS FUNDADORES DO PENSAR LATINO-AMERICANO DA COMUNICAÇÃO}

$\mathrm{Na}$ América Latina, a comunicação sempre foi outra coisa: um assunto não somente de meios ou tecnologias, mas de processos, práticas e experiências de cultura; mais do que jornalismo ou meios, comunicação. Em tempos de ditaduras e autoritarismos, a comunicação recorreu às heranças da sociologia, da política, da literatura, da arte, da antropologia; também, do diverso, do inquieto, do dissidente, do popular; porém, sobretudo quando era quase impossível ser livre na América Latina, a comunicação foi imaginada a partir de baixo, com 
as pessoas e pela libertação. O professor Jesús Martín-Barbero nos disse que a comunicação era mais sobre mediações do que sobre meios, mais sobre processos do que sobre objetos, e mais sobre pessoas do que sobre emissores. Assim, surge uma comunicação liberada dos meios de comunicação e de seus efeitos, no qual o importante é o processo no qual as comunidades produzem, circulam, questionam, mantêm e transformam significados; uma comunicação feita mais de gente do que de tecnologias ou meios.

Assim, a investigação e a criação em comunicação e cultura na América Latina conseguiram autonomia acadêmica e desenvolveram metodologias, conceitos e experiências próprias que permitiram responder a nossas próprias perguntas e realidades. Porém, não foi somente Jesús Martín-Barbero que levantou tal discussão. Houve muitos que pensaram com a cabeça voltada à América Latina, que produziram teoria a partir desse lugar de enunciação.

Todo mapa é subjetivo e feito de afetos, ou seja, é pouco científico, e além disso, apenas quem o habita sabe como ele é; para os demais ele é ficção. Por isso, o mapa que irei esboçar terá muitos esquecimentos e equívocos, meus e de ninguém mais. Quero fazer esse mapa como homenagem àqueles e àquelas que nos ensinaram a pensar de outro modo a comunicação, que nos abriram o caminho e nos colocaram no mundo, que nos disseram que no Sul se pensa, investiga e cria de outras formas e com outras paixões. Este mapa precário apresenta, à maneira de zapping, alguns dos autores mais significativos e algumas de suas ideias, com as quais temos construído o campo da comunicação na América Latina:

Antonio Pasquali (Venezuela): levou-nos da informação à comunicação.

Paulo Freire (Brasil): a partir dos diálogos do oprimido nos falou da necessidade de propor a conversação entre diferentes saberes para conquistar a consciência crítica de alguém no mundo.

Mario Kaplún (Uruguai): disse-nos como na educação estava a potência da comunicação.

Rosa María Alfaro (Peru): descortinou a vitalidade das culturas no território e os modos inventivos de sobreviver com dignidade na América da exclusão.

Armand Mattelart (Chile): alertou-nos sobre o império e seus modos de dominação cultural.

Luis Ramiro Beltrán (Bolívia): documentou o campo e nos comprometeu a construir outro mundo possível.

Marita Matta (Argentina): testemunhou como somos um continente de oralidades que encontrou no rádio nosso melhor relato de identidade e política.

Eliseo Verón (Argentina): disse-nos como as mensagens dos meios, numa perspectiva social e política, devem ser lidas. 
Valerio Fuenzalida (Chile): descobriu que as pessoas davam utilidade às mensagens midiáticas conforme suas necessidades, suas expectativas e seus desejos de protagonismo social.

Renato Ortiz (Brasil): explicou-nos como habitamos as culturas do mundo sem perder os lugares locais de enunciação.

Guillermo Orozco (México): levou-nos às matrizes que residem nos jogos de sentido de consumir meios, pelos processos estruturantes e operadores de apropriação, leitura e sentidos.

Aníbal Ford (Argentina): fez da crítica política um programa para descortinar os jogos hegemônicos do poder e as navegações de sentido.

Rossana Reguillo (México): enunciou que os jovens sempre são o outro que nos espelha em nossas barbáries.

Immacolata Vasallo de Lopes (Brasil): continua investigando as telenovelas e nos propõe a compreendê-las como espaço de opinião pública e narrativa da nação.

Carlos Monsiváis (México): falou-nos dos usos expressivos do massivo feitos pelos populares e como os meios são atos de migração cultural.

Ismar de Oliveira Soares (Brasil): inventou a educomunicação como campo de diálogo entre a recepção qualificada dos meios, a educação popular, a articulação coletiva para a mudança social e a comunicação como política pública.

Arlindo Machado (Brasil) e Jorge La Ferla (Argentina): participaram do processo da arte, do vídeo e da televisão para propor o pensar em imagens como ação disruptiva para criar outras estéticas e narrativas do audiovisual, algumas mais do Sul.

Além deles, na atualidade, há mentes brilhantes, investigadores rigorosos e ensaístas sublimes, que continuam inventando o pensar e o fazer da comunicação na América Latina e a partir dela, como Micael Herschmann, George Yúdice, Angel Quintero, Pablo Semán e Pablo Alabárces que encontraram nas músicas e no popular outros ritmos de identidade e cultura. Ou Gustavo Gómez, Germán Rey, Guillermo Mastrini e Martín Becerra, com sua defesa pública da liberdade de expressão e denúncia da concentração midiática. Ou Clemencia Rodríguez, Florencia Saintout, Claudia Villamayor, Amparo Marroquín, Alfonso Gumucio-Dagron e Gabriel Kaplún, que continuam encontrando a voz cidadã e a vitalidade nos sujeitos da classe popular, estes do território para propor epistemologias do barro, do Sul e do precário. Ou os discursos mutantes de Rosalía Winocur, Carlos Scolari, Alejandro Piscitelli, Alberto Quevedo e Jorge González, que nos levam a imaginar as hipermediações nos mundos transmediais. Ou Martín Caparrós, Cristián Alarcón, Juan Villoro, Patricia Nieto, Maria Moreno e Marcela Turati, que se empenham em contar histórias a partir de um jornalismo em mudança. Ou Silvio Waisbord, 
Adriana Amado e Mario Riorda, que estudam os modos como a política tornou-se comunicação.

Tudo isso para testemunhar que a comunicação à latino-americana existe e que possui conceitos, processos e ritmos próprios. Minha ignorância deixou muitos autores de fora, pelo que me desculpo. Essa comunicação na América Latina se canta e se afirma, assim como na canção de Calle $13^{2}$ :

${ }^{2}$ Durante a conferência do autor, foi mostrado o vídeo da canção cuja letra é transcrita no artigo. Disponível em: <https:// goo.gl/TKLvKE>. Acesso em:

24 set. 2017. A conferência do autor está disponível em: <https://goo.gl/CXyhpC>. Acesso em: 24 set. 2017.

Un pueblo escondido en la cima,

mi piel es de cuero por eso aguanta cualquier clima.

Soy una fábrica de humo,

mano de obra campesina para tu consumo

Frente de frio en el medio del verano,

el amor en los tiempos del cólera, mi hermano.

El sol que nace y el día que muere,

con los mejores atardeceres.

Soy el desarrollo en carne viva,

un discurso político sin saliva.

Las caras más bonitas que he conocido,

soy la fotografía de un desaparecido.

Soy la sangre dentro de tus venas,

soy un pedazo de tierra que vale la pena.

soy una canasta con frijoles,

soy Maradona contra Inglaterra anotándote dos goles.

Soy lo que sostiene mi bandera,

la espina dorsal del planeta es mi cordillera.

Soy lo que me enseño mi padre,

el que no quiere a su patria no quiere a su madre.

Soy América latina,

un pueblo sin piernas pero que camina.

Tú no puedes comprar al viento.

Tú no puedes comprar al sol.

Tú no puedes comprar la lluvia.

Tú no puedes comprar el calor.

Tú no puedes comprar las nubes.

Tú no puedes comprar los colores. 


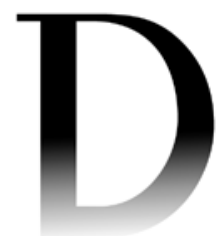

${ }^{3}$ Tradução literal: "Sou, / Sou o que deixaram, / sou a sobra do que roubaram. / Um povo escondido encima, / meu pé é de couro por isso aguenta qualquer clima. / Sou uma fábrica de transpiração, / mão de obra campesina para seu consumo / Frente fria no meio do verão, / o amor nos tempos de cólera, meu irmão. / O sol que nasce e o dia que morre, / com os melhores entardeceres. / Sou o desenvolvimento em carne viva, / um discurso político sem saliva. / As faces mais bonitas que já tem conhecido, / sou a fotografia de um desaparecido. / Sou o sangue dentro de suas veias, / sou um pedaço de terra que vale a pena. / Sou uma cesta com feijões, / sou Maradona contra a Inglaterra marcando dois gols. / Sou o que carrega minha bandeira, / a espinha dorsal do planeta é minha cordilheira.

/ Sou o que meu pai me ensinou, / aquele que não gosta de sua pátria não gosta de sua mãe. / Sou América Latina, / um povo sem pernas, mas que caminha / Você não pode comprar o vento. / Você não pode comprar o sol. / Você não pode comprar a chuva. / Você não pode comprar o calor. / Você não pode comprar as nuvens. / Você não pode comprar as cores. / Você não pode comprar minha alegria.

/ Você não pode comprar minhas dores. / Tenho lagos, tenho rios. / Tenho dentes para quando sorrio. / A neve que enfeita minhas montanhas. /

Tenho o sol que seca e a chuva que me banha. / Um deserto embriagado com peiote, um trago de pulque / Para cantar com os coiotes, tudo o que preciso. / Tenho meus pulmões respirando azul claro. / A altura que sufoca. / Sou os dentes de minha boca mascando coca. / O outono com suas

folhas deformadas. / Os versos escritos na noite estrelada.

/ Uma vinha repleta de uvas.
Tú no puedes comprar mi alegría.

Tú no puedes comprar mis dolores.

Tengo los lagos, tengo los ríos.

Tengo mis dientes pa' cuando me sonrío.

La nieve que maquilla mis montañas.

Tengo el sol que me seca y la lluvia que me baña.

Un desierto embriagado con bellos de un trago de pulque.

Para cantar con los coyotes, todo lo que necesito.

Tengo mis pulmones respirando azul clarito.

La altura que sofoca.

Soy las muelas de mi boca mascando coca.

El otoño con sus hojas desmalladas.

Los versos escritos bajo la noche estrellada.

Una viña repleta de uvas.

Un cañaveral bajo el sol en Cuba.

Soy el mar Caribe que vigila las casitas,

Haciendo rituales de agua bendita.

El viento que peina mi cabello.

Soy todos los santos que cuelgan de mi cuello.

El jugo de mi lucha no es artificial,

Porque el abono de mi tierra es natural.

Tú no puedes comprar al viento.

Tú no puedes comprar al sol.

Tú no puedes comprar la lluvia.

Tú no puedes comprar el calor.

Tú no puedes comprar las nubes.

Tú no puedes comprar los colores.

Tú no puedes comprar mi alegría.

Tú no puedes comprar mis dolores ${ }^{3}$.

Você não pode comprar o vento

Você não pode comprar o sol

Você não pode comprar chuva

Você não pode comprar o calor

Você não pode comprar as nuvens

Você não pode comprar as cores

Você não pode comprar minha felicidade 
Você não pode comprar minha tristeza

Tú no puedes comprar al sol.

Tú no puedes comprar la lluvia.

(Vamos dibujando el camino,

vamos caminando)

No puedes comprar mi vida.

MI TIERRA NO SE VENDE.

Trabajo en bruto pero con orgullo,

Aquí se comparte, lo mío es tuyo.

Este pueblo no se ahoga con marullos,

Y si se derrumba yo lo reconstruyo.

Tampoco pestañeo cuando te miro,

Para que te acuerdes de mi apellido.

La operación cóndor invadiendo mi nido,

¡Perdono pero nunca olvido!

(Vamos caminando)

Aquí se respira lucha.

(Vamos caminando)

Yo canto porque se escucha.

Aquí estamos de pie

¡Que viva Latinoamérica!

No puedes comprar mi vida ${ }^{4}$.

\section{CENA 2. JESÚS MARTÍN-BARBERO: MAPAS NOTURNOS E MEDIAÇÕES DIURNAS}

Nessa segunda cena, quero mencionar dois autores chave de nosso pensamento à latino-americana. Um é Néstor García Canclini, que nos abriu a mente para os cruzamentos culturais e nos ensinou: a pensar sobre o híbrido, a tentar fazer do consumo um lugar para pensar, a recuperar as perspectivas do popular nos seus jogos sedutores com a arte, a pensar a partir e na heterogeneidade multitemporal e cultural, a nos preocuparmos menos com o que se extingue do que com o que se transforma. O outro é Jesús Martín-Barbero que publicou há 30 anos Dos meios às mediações (De los medios a las mediaciones, 1987)
/ Um canavial sob o sol em Cuba. / Sou o mar do Caribe que vigia as casinhas. / Fazendo rituais de água benta. / $\mathrm{O}$ vento que penteia meu cabelo. / Sou todos os santos pendurados no meu pescoço. / O suco de minha luta não é artificial. / Porque o fertilizante de minha terra é natural. / Você não pode comprar o vento. / Você não pode comprar o sol. / Você não pode comprar chuva. / Você não pode comprar o calor. / Você não pode comprar as nuvens. / Você não pode comprar as cores. / Você não pode comprar minha felicidade. / Você não pode comprar minha tristeza".

\footnotetext{
${ }^{4}$ Tradução literal: "Você não pode comprar o sol. / Você não pode comprar a chuva. I (Vamos traçando o caminho, / vamos caminhando) / Não pode comprar minha vida. / MINHA TERRA NÃO SE VENDE. / Trabalho duro, mas com orgulho, / Aqui se divide, o meu é seu. / Esse povo não se afoga com marulhos, / E se se derruba, eu reconstruo. / Tampouco pisco quando te vejo, / Para que se lembre do meu sobrenome. / A operação condor invadindo meu ninho, / Perdoo, mas nunca esqueço! / (Vamos caminhando) / Aqui se respira luta. / (Vamos caminhando) / Eu canto porque se escuta. / Aqui estamos de pé / Que viva a América Latina! / Não pode comprar minha vida”.
} 


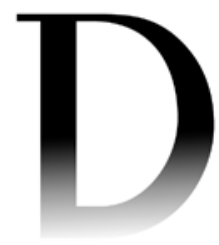

${ }^{5}$ No original: "mirar desde el otro lado: desde lo que hace la gente con lo que lee, con lo que mira, con lo que escucha".

${ }^{6}$ No original: "esos otros modos de ver, vivir y sentir".

${ }^{7}$ No original: "esa invisibilidad profunda desde la que vemos".

e nos obrigou a "abandonar" o midiacentrismo, o norte-americanismo e os dualismos morais de direita e esquerda. Inventou-se o termo mediações para articular o popular com o industrial e com o político. Realizou um calafrio epistemológico, como ele o chama, que implica mudar o lugar das perguntas (e dos olhares), que é passar a "mirar a partir do outro lado: desde o que as pessoas fazem com o que leem, com o que veem, com o que escutam" (Laverde Toscano; Aranguren Díaz, 1997: 154). Sua militância está "nesses modos outros de ver, viver e sentir"6 (Martín-Barbero; Corona, 2017; Huergo; Morawicki, 2016); nesses outros usos do massivo e nessas outras presenças sociais do corpo e das sensações. Tudo isso porque a comunicação é questão de cultura, portanto, de processos, práticas e re-conhecimentos mais do que de conhecimentos.

Agora me concentro em Jesús Martín-Barbero por três motivos: se fez latino-americano a partir da Colômbia, é colombiano, e sua obra Dos meios às mediações completa 30 anos. Na sequência está seu mapa noturno da comunicação que data de 1987 e o anúncio de seu novo mapa, que é visível a partir "dessa invisibilidade profunda a partir da qual vemos" (Martín-Barbero, 1998: 204), em 2017, quando a modernidade já não serve por ter deixado de iluminar o mundo com suas razões. Vivemos uma mutação cultural e surgem novas formas de pensar.

O mapa noturno da comunicação de Martín-Barbero data de 1987, quando publicou Dos meios às mediações e é este:

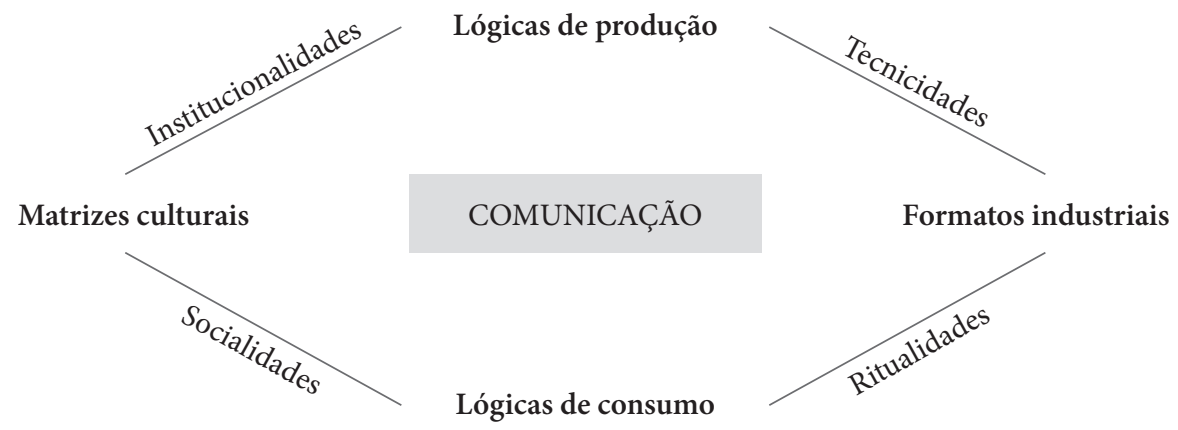

FIGURA 1 - Primeiro mapa noturno da comunicação

Fonte: Martín-Barbero (1987)

Um mapa feito de tensões e opacidades. Por um lado, a tensão mutante entre os formatos industriais com as matrizes culturais. Os formatos dão conta dos modos de fazer e produzir a comunicação e estão cheios de fórmulas, tecnicidades e invenções; formatos que se podem aprender porque respondem aos modos 
seriais de funcionamento da máquina da comunicação. Porém, esses formatos são significantes vazios, já que para produzir sentidos, prazeres e reconhecimentos requerem e exigem entrar em tensão com as matrizes culturais feitas de território, identidade, história e memórias. Por isso, não basta saber sobre o industrial e o técnico, é necessário converter-se em traficantes culturais, como afirma Estefanía González (colega de doutorado em Ciências Humanas e Sociais na Colômbia), em conhecedores de rituais e socialidades das comunidades e em conhecedores dos gostos populares para poder alcançar o milagre da conexão, produzir sentido e proporcionar prazer aos cidadãos.

A segunda tensão ocorre entre as lógicas de produção e as lógicas de consumo. As lógicas de produção são determinadas pela indústria, os graus de especialização dos processos técnicos, as políticas públicas e os saberes dos produtores. Aqui, o problemático não é o saber fazer, mas sim o tema das políticas públicas que podem buscar mais cidadania ou mais capital, mais concentração ou mais diversidade, mais liberdade e pluralidade ou mais controle e vigilância. Porém, não basta ter políticas públicas ou saberes industriais que determinam a produção, é preciso conhecer e entender os modos de recepção, consumo, desfrute, usos e interpelação que as pessoas fazem com o que veem, leem, ouvem e se conectam. Este é um âmbito ambíguo, poroso e mutante, tanto que nesta atualidade nos transformamos de audiências a programadores de nossos prazeres.

Esse mapa noturno nos permite navegar nas mediações diurnas da comunicação mais além de meios, tecnologias e efeitos, mais próximas da política, dos sentimentos, da cultura das pessoas; navegar criticamente na indústria e no poder, mas também nas submissões e no dualismo das direitas e esquerdas.

Porém, o século XXI chegou com suas mutações culturais de que nos falam Baricco, Martel, Ranciére e Serres, entre outros, que amplificaram os modos de comunicar, sentir e experimentar a conexão simbólica. Essas mutações das redes, os videojogos e as músicas. Essas da coprodução, o hipertexto, o fluxo, a interação e o viver conectado. Desse modo, Martín-Barbero nos propõe outro mapa: o do sensorium do século XXI, em homenagem a seu mestre Walter Benjamin, porque o que é necessário pensar são as transformações da sensibilidade e dos modos de percepção, ou o sensorium que irrompe na história, e disso é que são os estudos de comunicação.

Esse outro mapa coloca em cena outras tensões: o técnico que se joga contra e com as sensorialidades; os tempos provocam crise nos espaços. Esse mapa é uma novidade, por enquanto oral e com vislumbres em escritos, que ainda virá em forma de livro. 


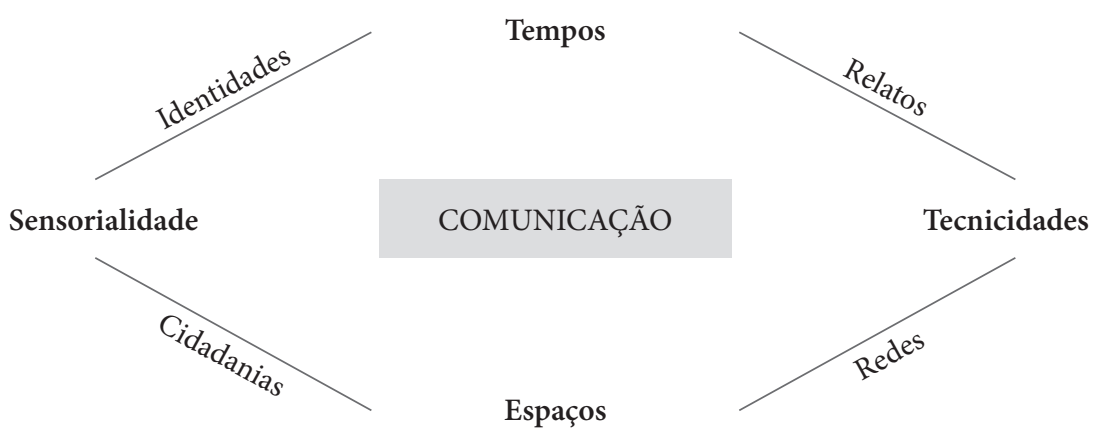

FIGURA 2 - Mais recente mapa noturno da comunicação

Fonte: Martín-Barbero

Esse mapa, para compreender o século XXI e sua mutação cultural, abrange outras tensões: a do fluxo, essa que é instável e diversa e que ocorre entre o sentir ou as sensações e as técnicas que a sociedade projeta para sentir; uma tensão entre o que formata e o que desprograma, entre as tensões e ambiguidades que se dão entre as redes e os relatos industriais e as identidades e cidadanias; a do olhar ao cidadão e às identidades como reservatórios de resistência e potência de existir de outros modos; da política como tática para obscurecer as notáveis transparências das redes, dos meios e das tecnocracias. A outra tensão indica que o tempo e o espaço já não são o que costumavam ser. Os espaços se transformaram de algo em que se vive para algo que perdura, multiplicaram-se e diversificaram-se, perdurando nos tempos. Enquanto isso, os cidadãos passam a experimentar temporalidades diversas simultaneamente: a das velocidades das redes até as lentidões ancestrais, da vertigem do videojogo à paciência do bem viver. Vive-se nos tempos, perdura-se em espaços.

Para concluir com a proposta de Martín-Barbero, somente me cabe lembrar essa fórmula que um dia ele nos contou: todo comunicador deve pensar com sua própria cabeça, ter algo a dizer e obter a atenção.

${ }^{8} \mathrm{O}$ tema do evento foi

"Transforming culture, politics \& communication: new media, new territories, new discourses" (N. do T.).

\section{CENA 3. DE BASTARDOS E CELEBRITIES}

Nessa última cena, tentaria expor minha própria ideia de contar, investigar, criar e imaginar nesta época. Como diz o título deste $\mathrm{IAMCR}^{8}$, estamos vivendo uma mutação cultural, política e comunicativa, que nós precisamos compreender. Os discursos e as agendas do século XX já são úteis para explicar as mudanças na sensibilidade de nossa época de populistas e empresários no poder, sociedade conectada por telefones móveis, redes digitais e gostos cool, mais do que por corpos e identidades grandiosas: democracia de clicks, likes, 
trending topics; um mundo cada vez mais rico financeiramente, porém com mais fome - a principal causa de morte no mundo é a fome, afirma Caparrós em Hambre (2015).

Precisamos de novos discursos, novas imaginações sociológicas, novas narrativas para apreender essa época zombie (cheia de vivos mortos como disse Beck). Um zumbi é a representação de um cadáver que de uma maneira ou de outra pode ressuscitar ou voltar à vida. Uma figura alucinante própria do culto vodu. Somos zombies porque nos acreditamos contraculturais, orgânicos e contra o consumo, ao mesmo tempo que consumimos a contracultura e o orgânico, e vivemos seguindo as telas negras (vivos mortos no consumo, basta ver a série Black mirror para compreender esses zombies); descremos da democracia, porque nos refugiamos em nosso eu-celebrity de selfie; abdicamos da densidade para brincar na cooltura. Somos zombies! Pensamos ser críticos, quando consumimos tudo o que o capital, o mercado e o entretenimento nos dita: hoje ser crítico e acreditar que o mundo conspira contra você é a lei que nos torna zombies. Somos zombies, porque acreditamos que basta ser cool, ter práticas orgânicas, discursos sobre a Mãe Terra, falar do "bem viver".

Precisamos de outros discursos para compreender e explicar a sociedade zombie em que nos convertemos. Somos cada vez mais os vivos mortos, porque cada vez mais a sociedade, seus discursos e seus jovens estão afastados da política e do humanismo; os meios de comunicação se desconectaram das pessoas e se converteram em atores políticos; a injustiça social e o cinismo estão na ordem do dia; o sistema jurídico é cada vez mais conservador, já que atua como um deus moral para defender o capital e a religião.

Para este novo mundo, para re-avivar os zombies, precisamos desenvolver diferentes discursos e conceitos, propor outros caminhos para compreender, explorar e narrar o destino que nos cabe. Já lembrei como os que vieram antes construíram outros modos de fazer, pensar, criar e investigar a comunicação a partir da América Latina. Agora, cabe a nós fazê-lo de outro modo: devemos reinventar politicamente os discursos da comunicação para que o zombie que todos temos interiormente reviva. Trata-se de ressuscitarmos por táticas mágicas - como o maravilhoso bem viver dos bolivianos, esse "Desde abajo, por la izquierda y con la Tierra" de Arturo Escobar (2016), os modos indígenas de conviver com a natureza e pensar como tecer, o \#niunamenos das mulheres argentinas, o \#estoapenascomienza dos jovens guatemaltecos. $\mathrm{O}$ zombie é um escravo que devemos libertar, e para isso devemos nos converter em feiticeiros capazes de compreender o que acontece fora da academia, e ir ao território para imaginar outros modos de estar nesse mundo. Aqui proponho um diálogo freiriano entre Jurassic Park (nós, os modernos) e The walking 
dead (os jovens e suas potencialidades para se libertarem do senhor), cada um ignorante do outro, porém com vontade de conhecê-lo para construir saberes entre iguais.

A comunicação já não é mensagem, propaganda, instrumento ou estratégia, é uma cultura de sequência e experiência, é um modo de viver a vida, é a prática narrativa do mundo. Não é algo extra, é algo que faz que signifiquemos: comunico, logo existo! é o novo tweet. Seu potencial é emocional, pois motiva as pessoas, permitindo a elas existir estética e narrativamente. Como vivemos a expressividade amplificada, todos queremos e podemos comunicar. E não se trata da síndrome dos quinze minutos de fama de Warhol (para isso bastam os realities), mas a síndrome de ser alguém para alguns outros significativos (vizinhos, amigos, amados). É por isso que proponho que a comunicação é sobre a autoestima das pessoas e da comunidade, o que é muito político, porque as visibilidades descompromissadas importam muito para a visibilidade dos silenciados; e, por isso, o mais político é encher as telas de rostos e corpos invisíveis nos grandes meios e nas máquinas de estilo. Todos temos direito de estar nas telas, porém de estar nelas com nossas próprias estéticas, formas de dizer, afetos e narrativas, o que chamo de cidadanias celebrities.

A comunicação é, assim, uma tática política que amplia os modos, as estéticas e as políticas de enunciação midiática e de redes. Até o momento, as promessas da Telesur, da $\mathrm{Al} \mathrm{Jazeera,} \mathrm{da} \mathrm{Encuentro} \mathrm{(Argentina)} \mathrm{e} \mathrm{dos} \mathrm{meios} \mathrm{cidadãos} \mathrm{não}$ modificam a estética e os formatos do mainstream, pois acreditam que basta mudar o conteúdo. O problema, porém, é que os modos de contar o conteúdo e suas estéticas são ideológicos, já que os modos de preencher as telas seguem a norma imposta, o modelo de beleza, de corpo e as características do Ocidente: branco, macho e do Norte. Os cidadãos querem ser reconhecidos como as estrelas de suas vidas, de suas comunidades e de seus territórios. Por isso, aumentar a autoestima nas estéticas, nas vozes, nas narrativas, nos modos de dizer e nos afetos de cada cidadão e da comunidade significa conquistar poder na política dos afetos, ser reconhecido entre os que importam e construir tecido coletivo a partir dos saberes narrativos contra os medos impostos pela política e contra a invisibilidade pública dos meios e das redes massivas.

Essa proposta das cidadanias celebrities assume que não somos puros e transparentes em nossas identidades, gozos e prazeres: estamos vivos, temos muitos pais culturais, somos filhos de diversas referências simbólicas e estéticas. Por isso proponho que devemos nos assumir como culturas bastardas, filhos do pop e do popular, do folk e do culto, do populista e do subalterno, da arte e do típico, ou seja, que nossa comunicação é atravessada por muitos pais e que, se imitarmos cada pai, não encontraremos o nosso lugar no mundo. É por isso 
que o fracasso de grande parte da comunicação que fazemos e estudamos ocorre porque queremos ser como os pais USA, Europa, Miami, homem, ocidental, branco. Essa inconsciência de sermos filhos culturais de muitos pais não é perversa, o patético é querer ser como eles sem nem saber como nós próprios somos... A única possibilidade que nos resta como bastardos é assumir essa característica como lugar de enunciação, e a Mãe Terra, o território e a identidade de alguém como o lugar legítimo a partir do qual se enuncia, se cria, se investiga e se subverte. Somente na medida em que assumimos que narramos, contamos e investigamos a partir e nesse território poderemos subverter a ordem dos meios e das redes do mainstream.

Ciudadanias celebrities e culturas bastardas como táticas para intervir no mainstream da comunicação e re-avivar os zombies em que nos convertemos. Isso requer como critério que assumamos a comunicação como uma experiência mutante, uma ação mais de narrativas e estéticas do que de conteúdos e argumentações. Comunicar consiste, então, em descobrir os modos de narrar de cada realidade, pessoa, situação. Por isso, um comunicador é quem usa o corpo, hackeia os poderes, remixa os saberes, discoteca os sentimentos de uma sociedade.

Necessitamos de novos discursos da comunicação. A América Latina criou a sua própria história a partir do Sul, por isso temos de um lugar para nos inspirar. Chegou o nosso momento em que temos que produzir sentido como filhos dessas culturas bastardas e provedores de cidadanias celebrities. Para fazer isso é necessário recuperar a memória que mora conosco do afro, do indígena, do feminino, assim como essa vitalidade juvenil que é a América Latina. E recordar que, nos grupos populares, discute-se e argumenta-se contando histórias e utilizando o corpo, porque quem não conta está morto e pobre é quem não dança. Talvez, usando o corpo, libertemos o zombie que cada um traz em si. $\mathbf{M}$

\section{REFERÊNCIAS}

CAPARRÓS, M. El hambre. Barcelona: Anagrama, 2015.

ESCOBAR, A. Desde abajo, por la izquierda y con la Tierra. El País, 17 jan. 2016. Disponível em: <https://goo.gl/HJH5pL>. Acesso em: 24 set. 2017.

HUERGO, J.; MORAWICKI, K. Memoria y promesa: conversaciones con Jesús Martín Barbero. La Plata: Universidad Nacional de La Plata, 2016.

LAVERDE TOSCANO, M. C.; ARANGUREN DÍAZ, F. Los mapas diurnos y nocturnos de Jesús Martín-Barbero. Nómadas, Bogotá, n. 7, p. 145-169, set. 1997. Disponível em: <https://goo.gl/NZGSb7>. Acesso em: 24 set. 2017. 


\section{Mutações bastardas da comunicação}

MARTÍN-BARBERO, J. De los medios a las mediaciones: comunicación, cultura y hegemonía. México: Gustavo Gilí, 1987.

De la comunicación a la filosofía y viceversa: nuevos mapas, nuevos retos. In: LAVERDE TOSCANO, M. C.; REGUILLO, R. (dir.). Mapas nocturnos: dialogos con la obra de Jesús Martín Barbero. Bogotá: Siglo del Hombre Editores, 1998. p. 201-221. DOI: https://doi.org/10.4000/books.sdh.153

MARTÍN-BARBERO, J.; CORONA BERKIN, S. Ver con los otros: comunicación intercultural. México: Fondo de Cultura Económica, 2017.

Artigo recebido em 11 de setembro de 2017 e aprovado em 22 de setembro de 2017. 